\title{
Transforming growth factor beta activity in urine of patients with type 2 diabetes and diabetic nephropathy
}

\section{E.W.R. Rivarola ${ }^{1}$, \\ M. Moyses-Neto ${ }^{1}$, \\ M. Dantas ${ }^{1}$, C.G. da-Silva², \\ R. Volpini ${ }^{2}$ and \\ T.M. Coimbra²}

Departamentos de ${ }^{1}$ Clínica M édica and

2Fisiologia, Faculdade de Medicina de Ribeirão Preto, Universidade de São Paulo, Ribeirão Preto, SP, Brasil

\section{Correspondence \\ T.M. Coimbra \\ Departamento de Fisiologia \\ Faculdade de Medicina de \\ Ribeirão Preto, USP \\ 14049-900 Ribeirão Preto, SP \\ Brasil}

Presented at the XIV Annual Meeting of the Federação de Sociedades de Biologia Experimental, Caxambu, MG, Brasil, August 25-28, 1999.

Research supported by FAPESP (No. 97/0515-6).

Received April 8, 1999 Accepted September 21, 1999

\section{Abstract}

Diabetic nephropathy (DN) is characterized structurally by progressive mesangial deposition of extracellular matrix (ECM). Transforming growth factor- $\beta$ (TGF- 3 ) is considered to be one of the major cytokines involved in the regulation of ECM synthesis and degradation. Several studies suggest that an increase in urinary TGF- $\beta$ levels may reflect an enhanced production of this polypeptide by the kidney cells. We evaluated TGF- $\beta$ in occasional urine samples from 14 normal individuals and 23 patients with type 2 diabetes (13 with persistent proteinuria $>500 \mathrm{mg} / 24 \mathrm{~h}$, DN, 6 with microalbuminuria, DMMA, and 4 with normal urinary albumin excretion, DMN) by enzyme immunoassay. An increase in the rate of urinary TGF- $\beta$ excretion (pg/mg $\mathrm{U}_{\text {Creat. }}$ ) was observed in patients with DN (296.07 \pm 330.77) $(\mathrm{P}<0.001)$ compared to normal individuals $(17.04 \pm 18.56)$ (Kruskal-Wallis nonparametric analysis of variance); however, this increase was not observed in patients with DMMA $(25.13 \pm 11.30)$ or in DMN $(18.16 \pm 11.82)$. There was a positive correlation between the rate of urinary TGF- $\beta$ excretion and proteinuria $(r=0.70, \alpha=0.05)$ (Pearson's analysis), one of the parameters of disease progression.
Key words

- TGF-ß urinary excretion

- Type 2 diabetes

- Proteinuria

- Diabetic nephropathy

- Extracellular matrix
Diabetic nephropathy (DN) is characterized structurally by renal hypertrophy and by progressive mesangial deposition of extracellular matrix (ECM) characterizing glomerulosclerosis (1), which is associated with progressive glomerular capillary occlusion, albuminuria and a progressive fall in glomerular filtration rate (GFR). These alterations are probably of multifactorial etiology, and hemodynamic, metabolic, or genetic factors have been proposed to explain them (2).

Several lines of experimental and clinical evidence suggest that transforming growth factor- $\beta$ (TGF- $\beta$ ) may play a causative role in the development of glomerulosclerosis and interstitial fibrosis observed in the course of many renal diseases (3-6). TGF- $\beta$ has been considered as a major cytokine involved in the regulation of ECM synthesis and degradation (7). This polypeptide can stimulate the synthesis of ECM components, including collagen, fibronectin and proteoglycans $(7,8)$ and block matrix degradation (7), thus promoting ECM accumulation. Overproduction of TGF- $\beta$ has been observed in many exper- 
imental and human kidney diseases (5,6,911). Border et al. $(3,5)$ reported that the administration of an antiserum capable of neutralizing TGF- $\beta$ or of decorin, a natural TGF- $\beta$ inhibitor, prevented the increased production of matrix proteins by glomerular cells and blocked ECM accumulation in a rat model of mesangial glomerulonephritis. It was also shown that in vivo transfection of the TGF- $\beta$ gene into the rat kidney led to increased production of TGF- $\beta_{1}$ in glomeruli associated with a rapid development of glomerulosclerosis (6).

The results of some clinical and experimental studies have suggested that the measurement of urinary TGF- $\beta$ content could be a useful noninvasive procedure for the evaluation of the renal production of this polypeptide $(12,13)$. In a previous study we observed an increase in urinary TGF- $\beta$ activity in patients with glomerulonephritis (13). In the present study we evaluated TGF- $\beta$ activity in urine from patients with type 2 diabetes and its correlations with albuminuria and plasma creatinine levels.

Patients were selected from those attending our outpatient clinic or admitted to Hospital das Clínicas de Ribeirão Preto. Spot urine samples were collected from 23 patients with type 2 diabetes ( 13 with persistent proteinuria $>500 \mathrm{mg} / 24 \mathrm{~h}, \mathrm{DN}, 6$ with microalbuminuria, urinary albumin excretion rate $>20$ and $<200 \mu \mathrm{g} / \mathrm{min}$, DMMA, and 4 with normal urinary albumin excretion, DMN) and from 14 normal individuals. The age range of the 23 patients was 19-57 years and the age range of the controls was 22-51 years. The range of creatinine levels of our patients was $0.6-3.0 \mathrm{mg} / \mathrm{dl}$ and the range of proteinuria 0.06-4.5 g/24 h. Plasma glucose levels assessed by the glycosylated hemoglobin test were well controlled in all patients. The patients had not been taking angiotensin II (AII) converting enzyme inhibitor or AII antagonist drugs for at least 15 days before urine collection. After TGF- $B$ determination, these medications were in- troduced for some of these patients. All control subjects had normal albuminuria, plasma creatinine levels and arterial pressure. The research was approved by the Ethics Committee of Hospital das Clínicas de Ribeirão Preto and informed consent was obtained from all individuals.

The urine samples were treated with 1 $\mathrm{mM}$ phenylmethylsulfonyl fluoride (Sigma Chemical Co., St. Louis, MO, USA) and aliquots were taken for urine creatinine determination and centrifuged at 2,000 rpm in a clinical centrifuge for $5 \mathrm{~min}$ at $4^{\circ} \mathrm{C}$. To measure total (latent + active) TGF- $B$ activity, $\mathrm{HCl}$ was added to the sample until $\mathrm{pH} 2.5$ to 2.0 was obtained. After $30 \mathrm{~min}$ at room temperature, the $\mathrm{pH}$ was readjusted to 7.4 with $\mathrm{NaOH}$. Quantification of TGF- $\beta$ in these samples was performed by enzyme-linked immunosorbent assay (ELISA) using kits from Promega Corp. (Madison, WI, USA) (14).

Urinary TGF- $\beta$ excretion is reported as urinary TGF- $\beta$ excretion/mg urinary creatinine to correct the variation in urine concentration. To construct a standard curve, known amounts of human recombinant TGF- $\beta_{1}$ (Promega Corp., Madison, WI, USA) were added to each well. The response was linear and presented a positive correlation between the amount of this polypeptide and optic density $(r=0.998)$.

Albumin was measured by electroimmunoassay in urine samples collected during a 24-h period (15) using an antibody against human albumin. The investigation was performed 3 times in each patient. Urinary creatinine was measured by the method of Jaffé (16).

The nonparametric analysis of variance proposed by Kruskal-Wallis was used to compare the various groups, with the level of significance set at 0.05 . The Pearson correlation coefficient was used to examine any significant correlation between the rate of urinary TGF- $\beta$ excretion and plasma creatinine levels and albumin in urine. Data are 
expressed as mean $\pm \mathrm{SD}$.

A significant increase in the rate of urinary TGF- $\beta$ excretion $\left(\mathrm{pg} / \mathrm{mg} \mathrm{U}_{\text {Creat. }}\right.$ ) was observed in patients with type 2 diabetes with persistent proteinuria, DN (296.07 \pm 330.77) $(\mathrm{P}<0.001)$ compared to normal individuals (17.04 \pm 18.5$)$; however, this increase was not observed in patients with microalbuminuria, DMMA $(25.13 \pm 11.30)$ or with normal albumin excretion, DMN (18.16 \pm 11.82$)$ (Figure 1).

A significant positive correlation was found between the amount of TGF- $\beta$ in urine and proteinuria in patients with type 2 diabetes (Figure 2) ( $r=0.70, \alpha=0.05)$. However, we did not find any correlation between the rate of urinary TGF- $\beta$ excretion and plasma creatinine levels.

The present results showed an increase in the rate of urinary TGF- $\beta$ excretion in patients with type 2 diabetes with persistent proteinuria $(>500 \mathrm{mg} / 24 \mathrm{~h})$. There was a wide variation in the rate of urinary TGF- $\beta$ excretion in these patients. However, these patients presented different stages and activity of renal disease.

Several studies have shown that TGF- $\beta$ may play a major role in glomerular disease, mediating the inflammatory response through glomerulosclerosis (4,5,9-11). Studies of in situ or in vitro hybridization and with immunohistochemical methods have demonstrated that the renal content of TGF- $\beta$ mRNA and TGF- $\beta$ protein was higher in many cases of experimental and clinical glomerulonephritis $(4,5,9-11)$. The consequences of the increase in TGF- $\beta$ production are multiple since this protein is known to have important effects on the synthesis of several matrix components and can block matrix degradation, thus promoting ECM accumulation $(7,8)$.

The pathogenetic mechanism(s) leading to increased renal TGF- $\beta$ production in diabetic patients are incompletely understood. Possibilities include glomerular hypertension and hypertrophy $(1,2,17)$, an increase in intrarenal renin content (18) and higher lev-

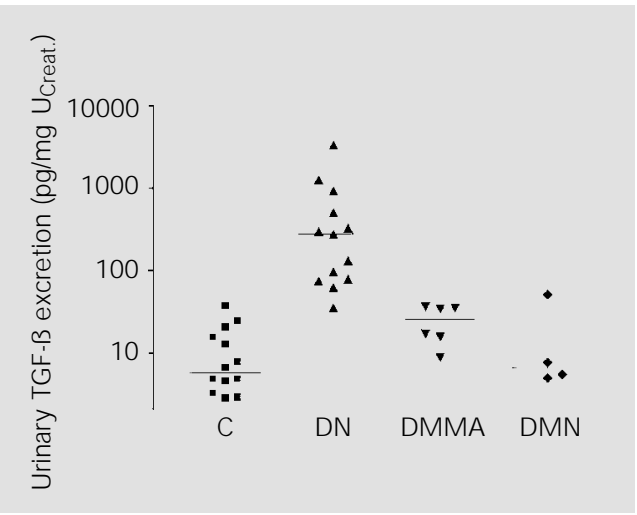

Figure 1 - Rate of urinary TGF-ß excretion for normal individuals (C, N = 14) and patients with type 2 diabetes with sustained proteinuria ( $\mathrm{DN}, \mathrm{N}=13)$, with microalbuminuria (DMMA, $\mathrm{N}=$ 6 ) or with normal urinary albumin excretion (DMN, $N=4$ ). TGF- $ß$ in urine samples was measured by ELISA using kits from Promega. $P=0.001$ for patients with type 2 diabetes (DN) compared to normal individuals and to DMMA and DMN (Kruskal-Wallis test). The median is shown as a horizontal line.

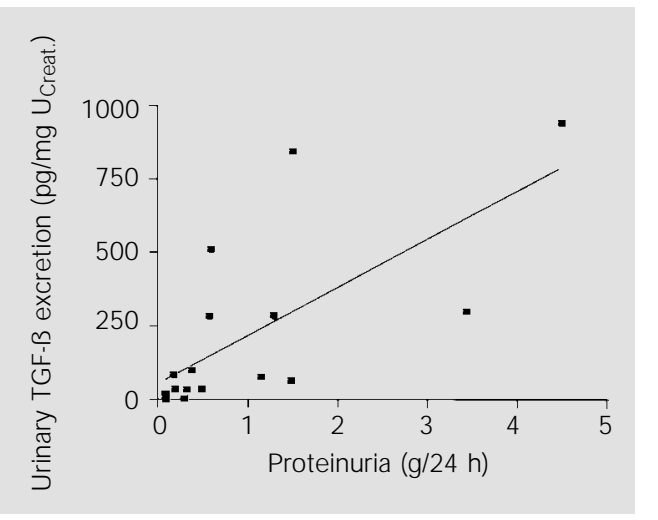

Figure 2 - Correlation between rate of urinary TGF-ß excretion and proteinuria observed in patients with type 2 diabetes. The correlation coefficient was $r=$ $0.70(\alpha<0.05$; Pearson's analysis).

els of glucose in plasma (19). It has been reported that stretching of rat mesangial cells by mechanical strain can provoke increased ECM and TGF- $\beta$ production (17). It has been recently demonstrated that AII (18) and glucose (19) can stimulate mesangial secretion of TGF- $B$. Some studies using mesangial cells in culture have shown that highglucose media can stimulate mesangial secretion of TGF- $\beta$, type IV collagen and other ECM components. It was also observed that AII stimulates rat glomerular mesangial cell production of type I collagen, fibronectin and biglycan through an induction of TGF- $\beta$ expression. Taken together, these data suggest that diabetic nephropathy may result from an interplay of mechanical, metabolic and humoral factors.

The present data show that the amount of TGF- $\beta$ in urine was significantly correlated 
with proteinuria. There are some observations suggesting that urinary TGF- $\beta$ derives from renal biosynthesis and not from ultrafiltration or secretion $(12,13,20)$. The amount of total TGF- $\beta$ (latent + active) is negligible in plasma and the amount of active TGF- $B$ is undetectable (20). Noh et al. (12) observed that urinary TGF- $\beta$ activity is related to the extent of scarring in crescentic nephritis in rabbits. In recent studies we observed a significant positive correlation between the rate of urinary TGF- $\beta$ excretion and the incidence of glomerulosclerosis in patients with glomerulonephritis (13). These data suggest that the increase of urinary TGF- $\beta$ activity observed in these patients may reflect enhanced production of this polypeptide by kidney cells or an increase in its renal content. Therefore, the measurement of the urinary activity of this polypeptide may be an early indicator for the evaluation of kidney disease progression.

\section{References}

1. Parving $\mathrm{H}-\mathrm{H}$, Osterby $\mathrm{R}$, Anderson $\mathrm{PW} \&$ Hsueh WA (1996). Diabetic nephropathy. In: Brenner BM \& Rector FC (Editors), The Kidney. 5th edn. Saunders, Philadelphia, 1864-1892.

2. Zatz R, Dunn BR, Meyer TW, Anderson S, Rennke HG \& Brenner BM (1986). Prevention of diabetic glomerulopathy by pharmacological amelioration of glomenular capillary hypertension. J ournal of Clinical Investigation, 77: 1925-1930.

3. Border WA, Okuda S, Languino LR, Sporn MB \& Ruoslahti E (1990). Suppression of experimental glomerulonephritis by antiserum against transforming growth factor-ß3. Nature, 346: 371-374.

4. Coimbra TM, Wiggins RC, Noh J W, Merritt S \& Phan S (1991). Transforming growth factor-ß production in anti-glomerular basement membrane disease in the rabbit. American J ournal of Pathology, 138: 223-234.

5. Border WA, Noble NA, Yamamoto T, Harper J R, Yamaguchi Y, Pierschbacher MP \& Ruoslahti E (1992). Natural inhibitor of transforming growth factor $B$ protects against scarring in experimental kidney disease. Nature, 360: 361-364.

6. Isaka Y, Fujiwara Y, Ueda N, Kaneda Y, Kamada T \& Imai E (1993). Glomerulosclerosis induced by in vivo transfection of transforming growth factor-ßs or platelet derived growth factor gene into the rat kidney. J oumal of Clinical Investigation, 92: 2597-2601.

7. Roberts $A B, M c C$ une $B K \&$ Sporn $M B$
(1992). Regulation of extracellular matrix. Kidney International, 41: 557-559.

8. Border WA, Okuda S, Languino LR \& Ruoslahti E (1990). Transforming growth factor- $\beta$ regulates production of proteoglycans by mesangial cells. Kidney International, 37: 689-695.

9. Yamamoto T, Nakamura T, Noble NA, Ruoslahti E \& Border WA (1993). Expression of transforming growth factor- $\beta$ is elevated in human and experimental diabetic nephropathy. Proceedings of the National Academy of Sciences, USA, 90: 1814-1818.

10. Niemir Z, Stein $H$, Noronha IL, Kruger $C$, Andrassy K, Ritz E \& Waldeher R (1995). PDGF and TGF- $\beta$ contribute to the natural course of human IgA glomerulonephritis. Kidney Intemational, 48: 1530-1541.

11. Bertoluci MC, Schmid H, Lachat JJ \& Coimbra TM (1996). Transforming growth factor- $\beta_{1}$ in the development of rat diabetic nephropathy. A 10 month study with insulin-treated rats. Nephron, 74: 189-196.

12. Noh J W, Wiggins RC \& Phan SH (1993). Urine transforming growth factor-ß activity is related to the degree of scarring in crescentic nephritis in rabbit. Nephron, 63: 73-78.

13. Dominguez GCS, Costa RC, Dantas $M$, Kimachi T, Piucci CR \& Coimbra TM (1998). Transforming growth factor beta activity in urine of patients with glomerulonephritis is related to their renal functional and structural changes. Nephrology, 4: 31-36.
14. Danielpour D, Dart LL, Flanders KC, Roberts AB \& Sporn M (1989). Immunodetection and quantitation of two forms of transforming growth factor beta (TGF- $\beta_{1}$ and TGF- $\beta_{2}$ ) secreted by cells in culture. J oumal of Cellular Physiology, 138: 79-86.

15. Laurell CB (1972). Electroimmunoassay. Scandinavian J ournal of Laboratory Investigation, 124 (Suppl): 21-23.

16. Haygen HN (1953). The determination of endogenous creatinine in plasma and urine. Scandinavian J oumal of Clinical and Laboratory Investigation, 5: 48-57.

17. Cortes $P$, Riser BL, Zhao $X \&$ Narins RG (1994). Glomerular volume expansion and mesangial cell mechanical strain: Mediators of glomerular injury. Kidney International, 45 (Suppl): S11-S16.

18. Kagami S, Border WA, Miller DE \& Noble NA (1994). Angiotensin II stimulates extracellular matrix protein synthesis through induction of transforming growth factor-ß expression in rat glomerular mesangial cells. J oumal of Clinical Investigation, 93: 2431-2437.

19. Cohen MP \& Zyiadeh FN (1994). Amadori glucose adducts modulate mesangial cell growth and collagen gene expression. Kidney International, 45: 475-484.

20. Grainger D, Mosedale DE, Metcalfe JC, Weissberg PL \& Kemp PR (1995). Active and acid-activatable TGF-ß in human sera, platelets and plasma. Clinica Chimica Acta, 235: 11-31. 